\title{
CONSTRUCTION OF RISK ASSESSMENT MODEL FOR CHARACTERISTIC TOWN PPP PROJECT IN THE OPERATION STAGE BASED ON IMPROVED MATTER ELEMENT MODEL--FROM THE PERSPECTIVE OF SOCIAL CAPITAL
}

\author{
WU yulu and YAO hui \\ junior students majoring in accounting, Nanjing Normal University, China \\ DOI: 10.46609/IJSSER.2021.v06i03.010 URL: https://doi.org/10.46609/IJSSER.2021.v06i03.010
}

\begin{abstract}
The application of PPP mode in characteristic town projects has become a hot trend in the development of characteristic towns, which is conducive to the formation of reasonable market competition and scientific allocation of social resources. However, at present, PPP mode makes it face more complicated risk environment than general project projects in the operation stage, and social capital is in a relatively inferior position. From the perspective of social capital, this paper uses decomposition analysis method to identify the risk factors of PPP characteristic town project operation stage, improves the weight judgment in matter-element model by interval hesitant fuzzy entropy, and constructs risk assessment model.
\end{abstract}

Keywords: matter element analysis, interval value hesitant fuzzy entropy, characteristic town, risk identification, risk assessment model.

\section{Introduction}

PPP is mainly used in the construction of public infrastructure, which refers to a kind of project mode in which social capital and the government cooperate together, social capital is responsible for the design, construction, operation, management and maintenance of infrastructure. The domestic PPP project is a kind of project cooperation supported by the government, which advocates pursuing the win-win between the government and the social investors. PPP projects used to be mainly used in infrastructure construction, such as highways, subways and so on, but now there is a growing use of PPP cooperation mode in the construction of special towns. Now the number and scale of the characteristic small town is expanding, many problems also come along with it. In the process of PPP project implementation, how to avoid the project aborting has become a common thinking problem. In order to avoid this situation, it is very important for the risk identification and evaluation management of the PPP project in the special small town. It 
International Journal of Social Science and Economic Research

ISSN: 2455-8834

Volume:06, Issue:03 "March 2021"

can identify the possible difficulties and make the countermeasures in advance, and it can greatly improve the success probability of the PPP project. The operation stage is also the key stage of whether the PPP project can be implemented successfully. Therefore, the risk identification and evaluation from the perspective of the social capital at this stage can help the social capital side evade the risk, provide more effective investment advice.

\section{Risk Identification}

From the perspective of social capital, this paper makes a risk identification and analysis on the characteristic small towns of PPP model. The direct stakeholders of PPP project in operation stage are still the government and social capital. So for social capital side, being able to identify and evaluate risks on the part of the government is very important for follow-up operations. The market has a great influence on the sustainable operation of the project, and the identification and evaluation of the market risk can help the project operation better. The risk of the project itself is the key to its successful implementation, and is essential to the risk identification of the project. In conclusion, we select the most direct impact in the operational phase of the project implementation of the four aspects of risk identification research.

\subsection{Method Selection}

Decomposition analysis is to simplify complex problems, facilitate the systematic development of things themselves and the inherent law. This paper uses decomposition analysis method to identify the risk of social capital in the running stage of PPP characteristic small town project, and gradually decomposes the risk and potential crisis of the project in every part of government, market, project and law.

\subsection{Risk Identification of Social Capital in Operation Stage of Special Small Town Project under PPP Mode}

\subsubsection{Government Risk}

As a stakeholder in PPP projects, the government has an influence on both micro and macro aspects of PPP projects, which is related to the formulation and implementation of PPP policies, the study of government risk is of great significance to the risk management of PPP characteristic small towns in the operation stage. Specifically:

(1) The government pays the risk: Part of the responsibility of the gap subsidy during the operation period is borne by the government. When the operation fee is insufficient, the government can take the vehicle purchase tax fund as a one-time government payment of riskoffset loan during the construction period. Although on the one hand can ease the social capital 


\section{International Journal of Social Science and Economic Research}

ISSN: $2455-8834$

Volume:06, Issue:03 "March 2021"

side of a certain financial pressure, but there will still be a timely payment or insufficient amount of the situation。

(2) The risk of government decision error: The government lacks PPP operation ability and experience, the Information asymmetry, the decision-making process is not standardized, the preparation work of the early stage of the project is insufficient, etc.

(3) Risk of delay in approval: the approval process will involve many departments, the approval process is more complex, so the time is too long, the cost is also high, to the normal operation of the project threat.

(4) Risks of inadequate government regulation: At present, the government adopts a single supervision model, the relevant institutions and departments are not clear about their functions and responsibilities, information is not public, the supervision of the institutions are not sound.

(5) Risk of project uniqueness: If the government approves the construction or alteration of other projects, it will form substantial commercial competition, which will lead to subsequent market income risk, credit risk and so on.

\subsubsection{Market Risk}

In the operation phase of PPP project, the market risk may lead to the discrepancy between the actual income and the expected income, and then affect the quality of the project. Specifically:

(1) Risk of fee change : Charge alteration the service or product of PPP project is too high or too low, the charge standard is not flexible, the project's operating income is not as expected.

(2) Risk of change in inflation: When encountered with inflation, prices rise, currency depreciation, affecting the operation of the project.

(3) Risk of changing market demand: The return of a project varies with changing market demand.

(4) Competitive Risk: With the development of PPP, the market share of similar projects will be threatened when the number of competitors increases.

\subsubsection{Project Risk}

For the social investors, whether the project can be profitable or not is the key to their investment decision. PPP projects are completed by the government in cooperation with the social investors. 


\section{International Journal of Social Science and Economic Research}

ISSN: $2455-8834$

Volume:06, Issue:03 "March 2021"

Such projects have their own advantages, but this does not mean that the project is infallible, the Risk Assessment of PPP project is very important in operation phase. Specifically:

(1) Lack of profitability: After the completion of the operation of the project, found that the project in the profitability deviation, unable to achieve the initial project set expectations, business is difficult to sustain.

(2) The project interest pursue contradiction: the project is made by the government and the social capital side together, but the government and the social capital side pursue different to the project final anticipated effect, in the operation stage very likely both contradictory phenomenon.

(3) The ability of the manager is not enough: The project operation requires high ability of the manager. If the manager can't manage the related affairs reasonably, it will affect the project completion.

(4) Late equipment maintenance: the town in the use of equipment in the late need to carry out related maintenance, if the facilities maintenance is not in place, will also lead to the project can not continue to operate.

(5) The concept of environmental protection is not enough: Modern Society is paying more and more attention to the concept of environmental protection, if the town does not take enough environmental protection facilities to protect the environment in operation, it will attract the attention of all sectors of society and affect the operation.

\subsubsection{Legal Risk}

As one of the risks running through the whole production cycle of PPP project, legal risk is also very important for its risk evaluation and management in the operation phase. Specifically:

(1) The risk that the legal system is not sound: In the operational phase, it may face various issues that need to be resolved by law, but the PPP project is still a relatively new form in China, and the relevant legal and regulatory system is still under construction, there may be a part of the emergency not included in the legal system, there is no legal basis for the situation.

(2) Changes in the Law: for the construction of the relevant laws in continuous improvement, there may be some changes, so the project is in the operational phase, how to deal with the risk of such legal changes is also very important.

(3) Illegal operation: in the implementation of management tools, the relevant legal issues may be unclear, the need to hire professional legal counsel for consultation, to resolve these legal doubts for the business has a great impact. 
International Journal of Social Science and Economic Research

ISSN: 2455-8834

Volume:06, Issue:03 "March 2021"

Table 1.Risk Evaluation Index System of Social Capital in Operation Stage of Special Small Town Project under PPP Mode

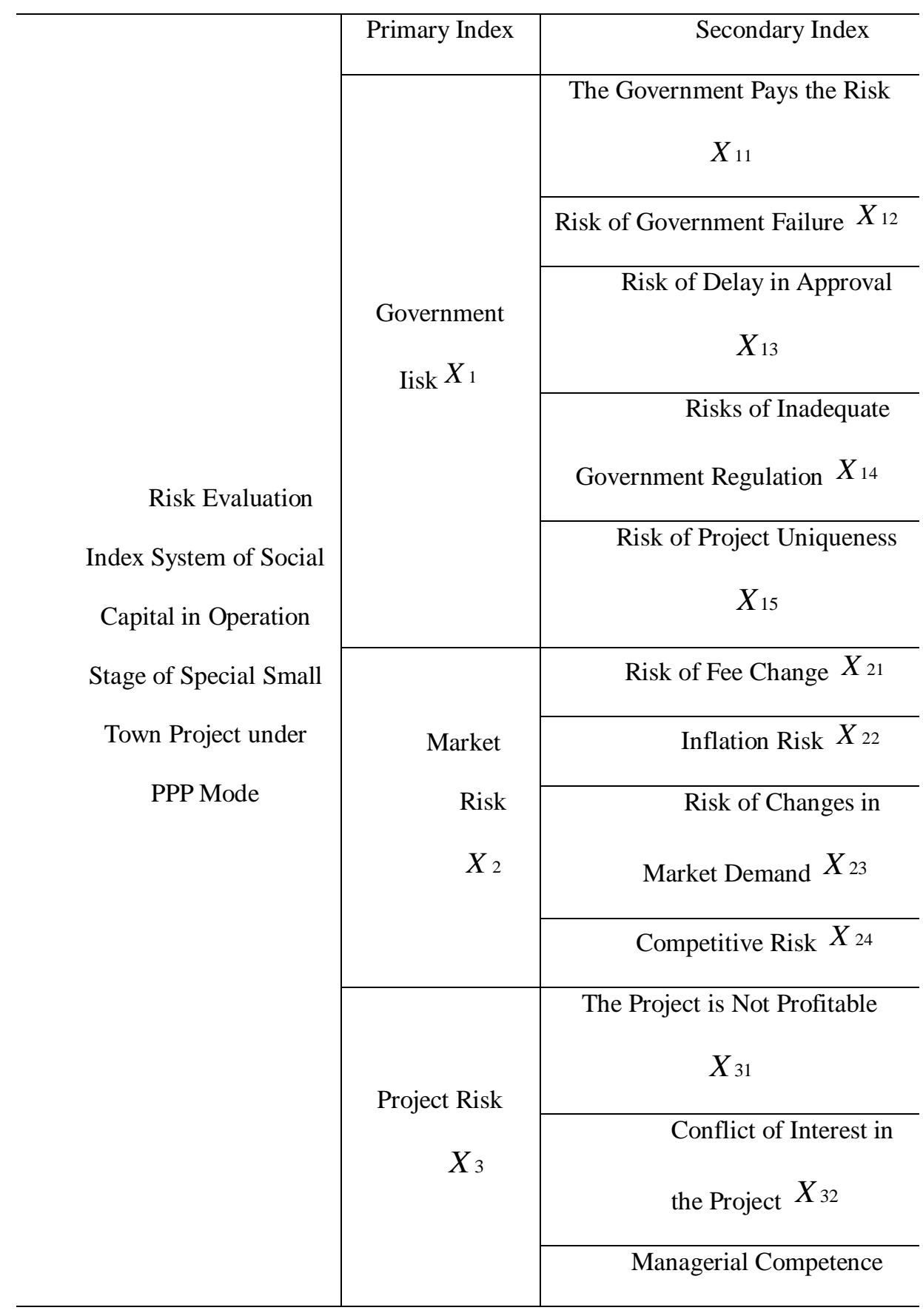




\begin{tabular}{|c|c|c|}
\hline & & $X_{33}$ \\
\hline & & $\begin{array}{c}\text { Insufficient Maintenance of Late } \\
\text { Equipment } X_{34}\end{array}$ \\
\hline & & $\begin{array}{l}\text { The Concept of Environmental } \\
\text { Protection is Insufficient } X_{35}\end{array}$ \\
\hline & \multirow{3}{*}{$\begin{array}{l}\text { Legal risk } \\
\qquad X_{4}\end{array}$} & $\begin{array}{c}\text { Risk of an Inadequate legal } \\
\text { system } X_{41}\end{array}$ \\
\hline & & $\begin{array}{l}\text { There's Been a Change } \\
\text { in the Law } X_{42}\end{array}$ \\
\hline & & Operations are Illegal $X_{43}$ \\
\hline
\end{tabular}

From Table 1, it can be seen clearly that there are 4 first-class indexes and 17 second-class indexes in the risk assessment index system of social capital in the operation stage of PPP characteristic small town project.

\section{Construction of Risk Assessment Model of Social Capital Side in PPP Characteristic Town Project Operation Stage Based on Improved Matter Element Model}

According to the traditional matter-element model, the improvement ideas are as follows:

The traditional matter-element model is difficult to carry out the reasonable and effective index weight, and the experts' scoring of the evaluation index weight is uncertain. In order to improve the rationality of the index weight, interval hesitant fuzzy entropy is introduced into the risk assessment model of PPP project. Interval hesitation fuzzy entropy can more accurately describe the hesitation phenomenon of experts in scoring, reduce the subjective impact of experts' scoring, and make the improved model more suitable for PPP characteristic town project risk assessment model.

Based on this, the construction steps of risk assessment model of social capital side in PPP characteristic town project operation stage are as follows:

Step 1: build the index system of risk assessment of social capital side in PPP characteristic town project operation stage 


\section{International Journal of Social Science and Economic Research}

ISSN: 2455-8834

Volume:06, Issue:03 "March 2021"

The risk assessment index system of social capital side in PPP characteristic town project operation stage is shown in Table 1.

Step2: determine the weight of risk assessment index system of social capital side in PPP characteristic town project operation stage

In the process of determining the weight of risk assessment index system of social capital side in PPP characteristic town project operation stage,

Let the weight distribution of the first level evaluation index be $a_{i}(\mathrm{i}=1,2,3,4)$, the weight vector of the first level index $A=\left(a_{1}, a_{2}, a_{3}, a_{4}\right)$, and satisfy $a_{i \geq 0}$ and $\sum_{i=1}^{4} a_{i}=1$; let the weight distribution of the second level evaluation index be $a_{i s} \quad\left(\mathrm{i}=1,2,3,4 ; s=1,2, \ldots, n_{i}\right)$, each secondary index weight vector $A_{i}=\left(a_{i 1}, a_{i 2}, \ldots, a_{i n}\right)$, and satisfy $a_{i s} \geq 0, \sum_{s=1}^{n_{i}} a_{i s}=1$. The specific calculation steps of interval hesitant fuzzy entropy weight are as follows:

$$
P_{i}=\frac{1}{\sqrt{2}-K} \sum_{i=1}^{K}\left(\sin \frac{\pi\left(P_{Q(1)}^{-}(x)+P_{Q(1)}^{+}(x)\right.}{4}+\cos \frac{\pi\left(P_{Q(1)}^{-}(x)+P_{Q(1)}^{+}(x)\right.}{4}-1\right)
$$

$\mathrm{K}$ is the total number of experts to score, $\mathrm{E}(\mathrm{K})$ is the score of the kth expert, ${ }^{-}{ }_{Q(1)}(x)$ representing the left part of interval hesitant fuzzy element, $P^{+} Q(1)(x)$ representing the right part of interval hesitant fuzzy element.

After calculating the interval hesitant fuzzy entropy of each risk index and substituting it into formula (2), the weight proportion of each risk index is obtained :

$$
w_{i}=\frac{1-Q_{i}}{\sum_{i=1}^{n} 1-Q_{i}}
$$

Step3: determining classical domain and node domain

This paper holds that the risk level of social capital in PPP characteristic town project operation stage can be divided into five levels, namely very high, high, medium, low and very low. 
Therefore, the evaluation indexes of social capital in the operation stage of PPP characteristic town project can be divided into five levels: Level 1, level 2, level 3, level 4 and level 5.

Under the government risk index $\left(X_{1}\right)$, the classical domains $R_{0 j}$ of each level are as follows:

$$
\begin{aligned}
& R_{01}=\left[\begin{array}{ccc}
\text { llevel } & X_{11} & 0-20 \\
& X_{12} & 0-20 \\
& X_{13} & 0-20 \\
& X_{14} & 0-20
\end{array}\right] R_{02}=\left[\begin{array}{ccc}
\text { 2level } & X_{11} & 20-40 \\
& X_{12} & 20-40 \\
& X_{13} & 20-40 \\
& X_{14} & 20-40
\end{array}\right] R_{03}=\left[\begin{array}{ccc}
3 \text { level } & X_{11} & 40-60 \\
& X_{12} & 40-60 \\
& X_{13} & 40-60 \\
& X_{14} & 40-60
\end{array}\right] \\
& R_{04}=\left[\begin{array}{ccc}
\text { 4level } & X_{11} & 60-80 \\
& X_{12} & 60-80 \\
& X_{13} & 60-80 \\
& X_{14} & 60-80
\end{array}\right] R_{05}=\left[\begin{array}{ccc}
5 \text { level } & X_{11} & 80-100 \\
& X_{12} & 80-100 \\
& X_{13} & 80-100 \\
& X_{14} & 80-100
\end{array}\right] \\
& R_{p 1=[\text { (government risk) ], }}=\left[\begin{array}{ll}
X_{11} & 0-100 \\
X_{12} & 0-100 \\
X_{13} & 0-100 \\
X_{14} & 0-100
\end{array}\right]
\end{aligned}
$$

The classical domain and node domain of each level under the other indicators can be similar.

Step4: determine the matter element to be evaluated

In the process of carrying out the risk assessment of the social capital side in the operation stage of PPP characteristic town, the risk assessment side invites experts to rate the risks faced by the social capital side in the operation stage of PPP characteristic town according to the above index system and evaluation standards, and record the value of each index $x_{i n}$. According to the listed index system, in the risk assessment of social capital side in the operation stage of characteristic town project under PPP mode, the number of material elements to be evaluated $\mathrm{m}$ is 5 . Let the object to be evaluated be $P_{m} \quad(\mathrm{~m}=0,1, \ldots, 4)$.Each calculation result is expressed by matter element $R_{m}$, which is called matter element to be evaluated. Then, under the PPP mode, the matter elements to be evaluated in the risk assessment of the social capital side in the operation stage of the characteristic town project are as follows: 


$$
\begin{aligned}
& R_{1}=\left[\begin{array}{ccc}
p_{1} & X_{11} & x_{11} \\
& X_{12} & x_{12} \\
& X_{13} & x_{13} \\
& X_{14} & x_{14} \\
& X_{15} & x_{15}
\end{array}\right] R_{2}=\left[\begin{array}{ccc}
p_{2} & X_{21} & x_{21} \\
& X_{22} & x_{22} \\
& X_{23} & x_{23} \\
& X_{24} & x_{24}
\end{array}\right] R_{3}=\left[\begin{array}{ccc}
p_{3} & X_{31} & x_{31} \\
& X_{32} & x_{32} \\
X_{33} & x_{33} \\
X_{34} & x_{34} \\
X_{35} & x_{35}
\end{array}\right] \\
& R_{4}=\left[\begin{array}{rrr}
p_{4} & X_{41} & x_{41} \\
X_{42} & x_{42} \\
X_{43} & x_{43}
\end{array}\right] \rho\left(x_{i}, x_{p i}\right)=\left|x_{i}-\frac{1}{2}\left(a_{p i}+b_{p i}\right)\right|-\frac{1}{2}\left(b_{p i}-a_{p i}\right)
\end{aligned}
$$

R0_-matter element evaluation of social capital side risk in PPP characteristic town project operation stage;

R1—matter element evaluation of government risk;

R2_evaluation matter element of market;

R3_-matter element of project risk assessment;

R4_matter element evaluation of legal risk;

xi $(i=1,2,3,4)-$ weighted value of first level index.

Step5: determine the correlation degree of each index of the matter element to be evaluated with respect to each grade $\mathbf{J}$

$$
\begin{aligned}
& K_{j}\left(x_{i}\right)= \begin{cases}\frac{\rho\left(x_{i}, x_{0 j i}\right)}{\rho\left(x_{i}, x_{p i}\right)-\rho\left(x_{i}, x_{0 j i}\right)}, & \text { if } \rho\left(x_{i}, x_{p i}\right)-\rho\left(x_{i}, x_{0 j i}\right) \neq 0 \\
-\rho\left(x_{i}, x_{0 j i}\right)-1, & \text { if } \rho\left(x_{i}, x_{p i}\right)-\rho\left(x_{i}, x_{0 j i}\right)=0\end{cases} \\
& \rho\left(x_{i}, x_{0 j i}\right)=\left|x_{i}-\frac{1}{2}\left(a_{0 j i}+b_{0 j i}\right)\right|-\frac{1}{2}\left(b_{0 j i}-a_{0 j i}\right) \\
& \rho\left(x_{i}, x_{p i}\right)=\left|x_{i}-\frac{1}{2}\left(a_{p i}+b_{p i}\right)\right|-\frac{1}{2}\left(b_{p i}-a_{p i}\right)
\end{aligned}
$$

$b_{0 j i} \_$upper limit of classical field;

$a_{0 j i} \_$lower limit of classical field 
$b_{p i}$

_ _ upper limit of node domain ;

$a_{p i} \_$lower limit of node domain.

In the above formula, $\rho\left(x_{i}, x_{0 j i}\right)$ is the distance between a point ${ }^{x_{i}}$ and an interval ${ }^{x_{0 j i}}$.

Step 6: calculate the relevance of things $P_{m}$ to be evaluated with respect to each grade j

If the weight coefficient of the index $X_{i \text { is }} a_{i}$, and $\sum_{i=1}^{n} a_{i}=1$, then $K_{j}(p)=\sum_{i=1}^{n} a_{i} K_{j}\left(x_{i}\right)$

$K_{j}(p)$ is the combination value of the correlation degree of each index with respect to each grade of the thing to be evaluated under the consideration of the index weight. This formula is not only the calculation model of the correlation degree of each evaluation module, but also the calculation model of the correlation degree of the whole thing to be evaluated.

Step 7: grading

If $K_{j_{0}}(p)=\max _{j \in(1,2, \ldots, m)} K_{j}(p)$ the evaluation $P_{m}$ belongs to grade $j_{0}$.

According to the above model, we can analyze the risk that social investors are most likely to cause loss in the operation stage, which can not only help investors to prevent and deal with the risk, but also help investors to choose more suitable investment projects, provide effective basis for risk response, and help projects to operate better.

\section{Conclusion}

Based on the improved matter-element model, this paper attempts to build a risk assessment system for the social capital side in the operation stage of characteristic town project under PPP mode. By using the above model in specific cases, we can analyze the risk that social investors are most likely to cause losses in the operation stage, which can not only help investors to prevent and deal with the risks, but also help investors Choose a more suitable investment project to provide an effective basis for risk response and help the project operate better.

\section{References}

[1] Chen Shuling. PPP Model Featured Town Risk Management - Take the Special Town of Zhile Fisheries as an Example of the Value Project, 2019, 38 (29): 95-97. 
[2] Liu Bo, ShenJuqin, Sun Fuhua. PPP Model Reducing the Operation Mode of Water Engineering Projects Selection Study. China Rural Water and Hydropower, 2017 (12): 140-144.

[3] Jiao Wei, Fu Weihui, ShenZhifeng. Dynamic Analysis of PPP Project Stakeholder Relationship Network from a Full Life Cycle Perspective, Project Management Technology, 2016, 14 (08): 32-37.

[4] Li Haizhu, Deng Ruixiang, Wang Sejong, Li Manchu, Ding Longting. DB pattern indicator weights based on interval value hesitant fuzzy entropy are determined. Journal of Civil Engineering and Management, 2019, 36 (05): 96-101.

[5] ZengXue, Koo Peng. Highway PPP Project Risk Evaluation Model Construction and Application - Based on Social Capital Perspectives, Residential and Real Estate, 2019 (06): 120121.

[6] Cheng Daohu. Study on the risk evaluation of the DB model of highway engineering based on the interval value hesitant fuzzy entropy-cloud model, Highway, 2020, 65 (11): 278-284.

[7] Cui Caiyun, Liu Yong, Xia Bo, et al. Overview of public-private partnerships in the wasteto-energy incineration industry in China: Status, opportunities, and challenges. 2020, :100584-. 